\title{
ISCHAEMIA COMPLICATING CLOSED TIBIAL AND FIBULAR SHAFT FRACTURES
}

\author{
R. Owen, Oswestry, England, and B. Tsimboukis, Athens, Greece \\ From the Robert Jones and Agnes Hunt Orthopaedic Hospital, Oswestry
}

This paper is concerned with a small part of the complex problem of fractures of the tibial and fibular shafts. Ischaemic changes add to the difficulties of management, but occasionally pass unrecognised. This subject is important because of the increasing frequency of high-speed injuries of the lower limb and because of the renewed interest in peripheral vascular repair in accident surgery (Hughes 1958, Bonney 1963, Kirkup 1963).

Nicoll (1964), in a report on 674 patients with tibial shaft fractures treated conservatively, said that contractures in the ankle and foot were rare and had been seen in five cases only. He believed that this complication was avoidable, a view which we can only partly supfcrt. We believe that, like Volkmann's ischaemia in the upper limb, ischaemic changes of varying degree involving the soft tissues of the calf are far more common than is usually realised. We also believe that disturbance of the vascular supply to the soft tissues is often unconnected with tight plasters and other external splints and that the precipitating lesion is deep seated and, once diagnosed, demands prompt surgical attention (Eastcott 1965).

We have seen acute Volkmann's ischaemia of the calf in two young men; two other late cases also were studied but the pathological details were too scanty to warrant detailed description. They are, however, included in the clinical review.

\section{CASE REPORTS}

Case 1-A schoolboy aged sixteen years sustained a closed oblique fracture at the junction of the middle and lowest thirds of the right tibia and fibula in a scooter accident (Fig. 1). There was moderate swelling of the soft tissues. The fractures were manipulated and the leg put into a full length padded plaster (Fig. 2). At first there was little discomfort, but on the fourteenth day the patient complained of cramp in the right calf. There was then no evidence of circulatory embarrassment in the foot, and dorsiflexion of the toes did not produce discomfort. However, because of the suspicious symptoms the plaster was changed. At twenty-eight days it was noticed that the toes were tending to curl, and in spite of a further change of plaster at eight weeks, there was a stubborn tendency for the foot to go into equinus (Fig. 3). Further, the fracture itself could not be adequately controlled and an antero-lateral angulation developed. The ankle, foot and toes were stiff, with an established pes equinovarus deformity. In spite of prolonged physiotherapy the patient walked badly and, although no further equinus occurred, it was thought that there was ischaemia in the posterior calf, with secondary contracture of the posterior and medial tissues giving rise to the classical foot and ankle deformity, and almost certainly accounting for the angulation at the fracture site (Fig. 4). Oscillometry of the right calf showed appreciable diminution in amplitude. The posterior tibial pulse was absent, and there were sensory changes in the distribution of the posterior tibial nerve.

At operation, through an antero-medial mid-calf approach, fibrous union of the tibial shaft was found; exploration of the posterior structures revealed an extensive mass of pulpy necrotic muscle involving the distal parts of the triceps surae, flexor hallucis longus, tibialis posterior and long toe flexors (Fig. 5). The dead muscle was removed. The posterior tibial 


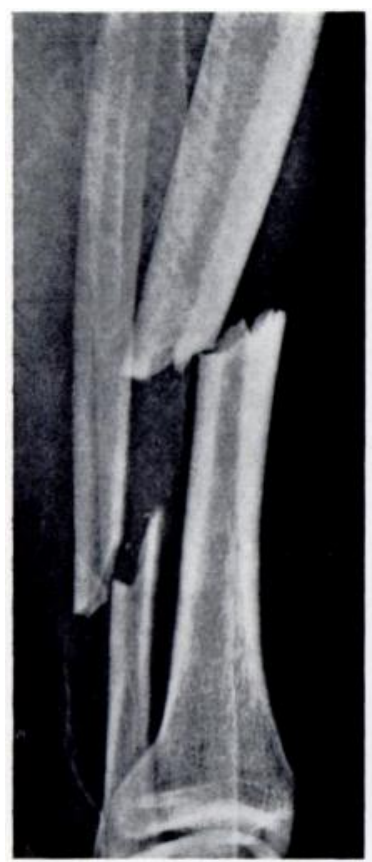

Fig. 1

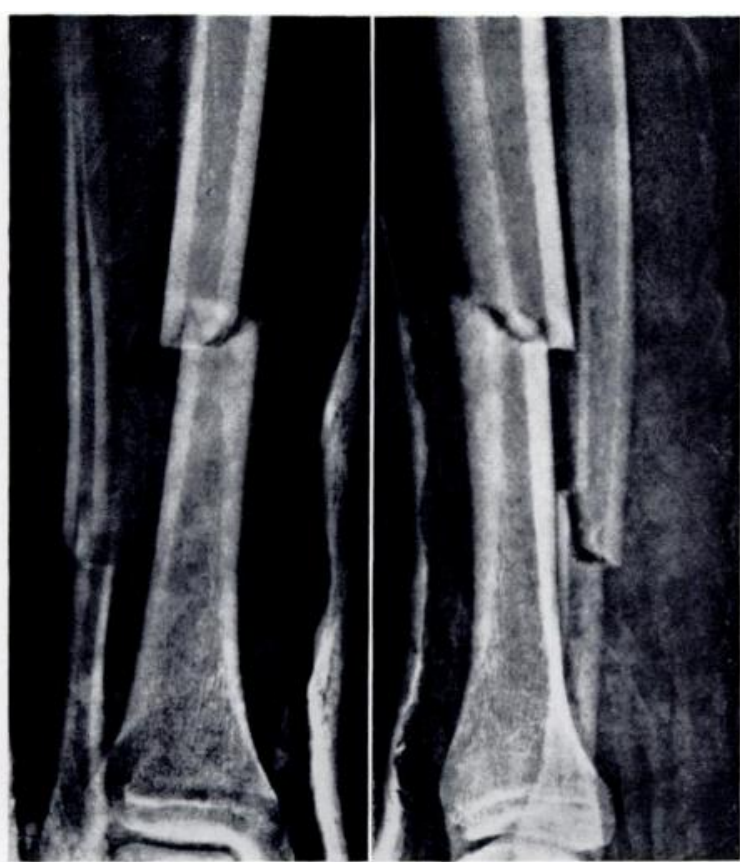

FIG. 2

Case 1. Figure 1-Radiograph of the fractured tibia and fibula. Figure 2-Radiographs of the fractures after reduction.

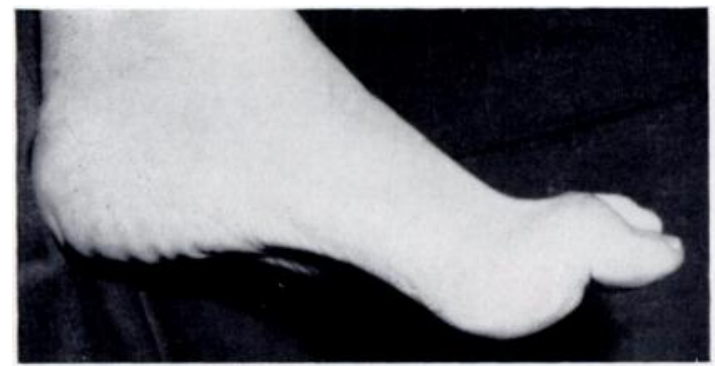

FiG. 3

Case 1-To show the early clawing of the toes and the equinus of the foot.

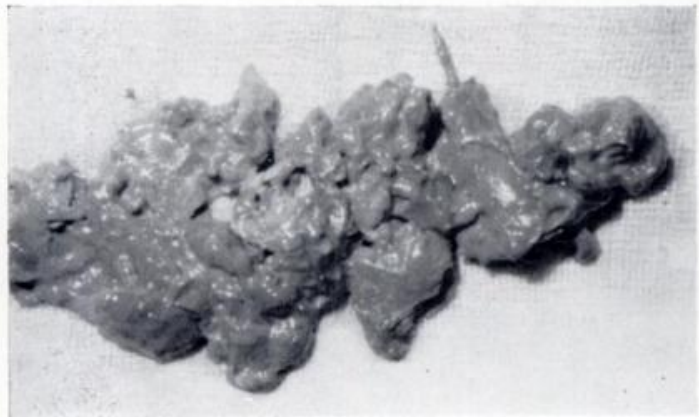

FIG. 5

Case 1-Macroscopic appearance of the dead muscle that was removed.

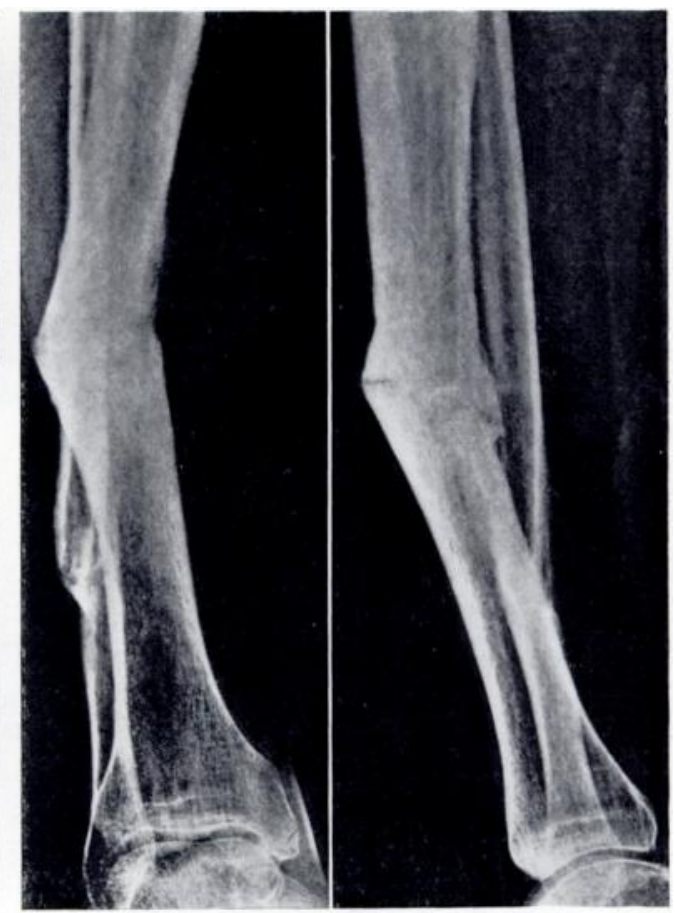

FIG. 4

Case 1-Radiographs showing the persistent anterolateral angulation deformity.

VOl. 49 B, NO. 2, MAY 1967 


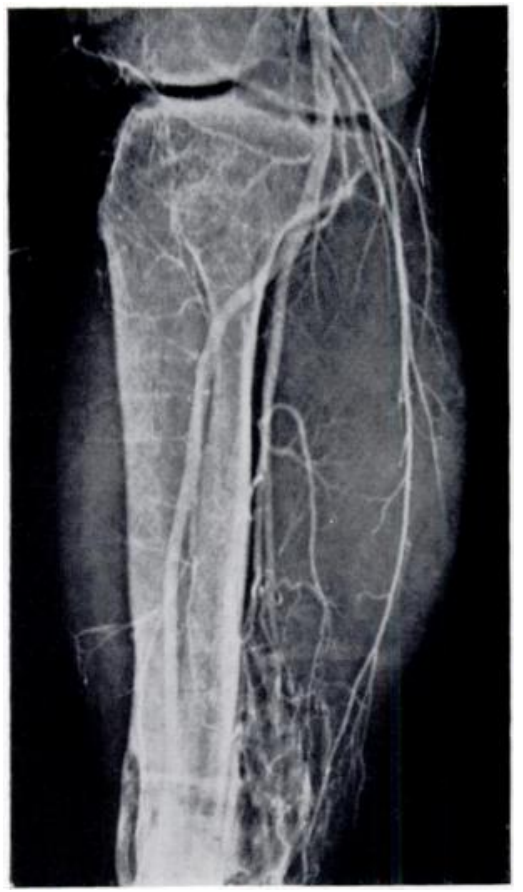

Fig. 6

vessels could not be identified, but the nerve was in continuity. Phemister-type bone grafting was done after correcting both the deformity of the tibia and foot. The leg was immobilised in plaster for four months, at the end of which time it was united. At six months the boy was walking well and had full movements of the knee. The position of the foot was acceptable, but there was moderate clawing of the toes. Electromyography confirmed that the extensor muscles of the foot were normal, but there was evidence of partial denervation of the short flexors and abductor of the big toe, consistent with the clinical finding of damage to the posterior tibial nerve. There was very poor activity in the posterior calf muscles. Femoral arteriography confirmed the clinical and operation findings (Fig. 6). Microscopy of the dead muscle was of little value; it showed completely necrotic amorphous muscle tissue with no identifiable cell structure.

FIG. 6

Case 1-Arteriograph showing lack of definition of the posterior tibial artery, with evidence of collateral flow.

Case 2-A youth aged seventeen years sustained an oblique fracture of the mid-shaft of the right tibia and fibula in a motor-cycle accident (Fig. 7). On admission there was much soft-tissue swelling and there were two puncture wounds anteriorly. The blood supply to the foot did not cause concern, and sensation was normal. Treatment consisted of wound toilet and application of a well padded plaster. Only moderate discomfort was suffered during the first week after injury. The first change of plaster was at five weeks. At fourteen weeks the fractures were consolidated and the limb was allowed free (Fig. 8). During the next week, however, the foot assumed a fixed equinus deformity. Despite manipulation under anaesthesia the deformity could not be corrected (Fig. 9). Oscillometry revealed diminished amplitude in the right calf. Arteriography confirmed that the posterior tibial and peroneal arteries had been damaged. A diagnosis of Volkmann's ischaemia was made.

At operation, through a posterior approach, eighteen weeks after the original injury, an area of necrosis was found involving the triceps surae and extending deeply into the muscle bellies of the long toe flexors and tibialis posterior (Fig. 10). Much tethering of the tendons behind the ankle and tibia necessitated tenolysis; the necrotic and yellow mass of muscle surrounded by the fibrous capsule was removed. The tendo calcaneus was lengthened and the foot brought up to neutral position. A padded plaster was applied which was removed at the fourth week. Progress was rapid after this, although residual mild clawing of the toes persisted. Electromyography showed a normal response in the extensors of the toes, but there was greatly diminished activity in the posterior calf muscles and to a lesser extent in the intrinsic muscles in the foot. Histology showed changes typical of Volkmann's ischaemia; in a mass of necrotic muscle individual fibres were still discrete but anucleate with no recognisable internal structure and they stained a uniform pink with haematoxylin and eosin (Fig. 10). Recently formed fibrous tissue was present around the periphery and in tongues projecting into the muscle sequestrum. Multinucleate giant cells engaged in phagocytosing dead muscle fibres lay around the edge of the necrotic mass (Fig. 11). There was no evidence of muscle cell regeneration, although Le Gros Clark (1946) believed that such can occur at the edges by budding and amitotic fission of mature muscle fibres. 


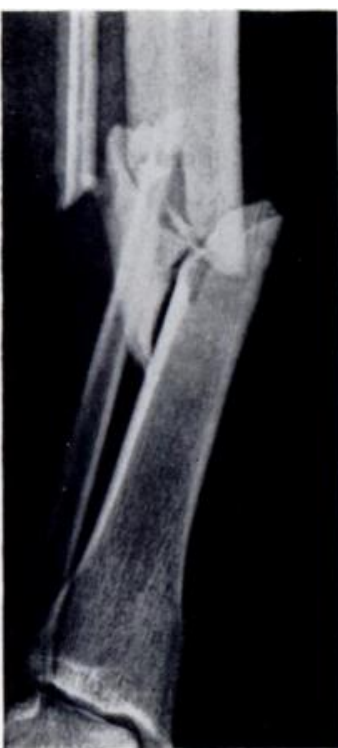

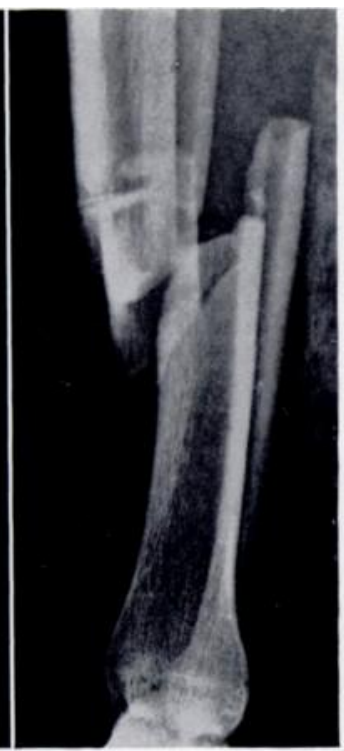

Fig. 7

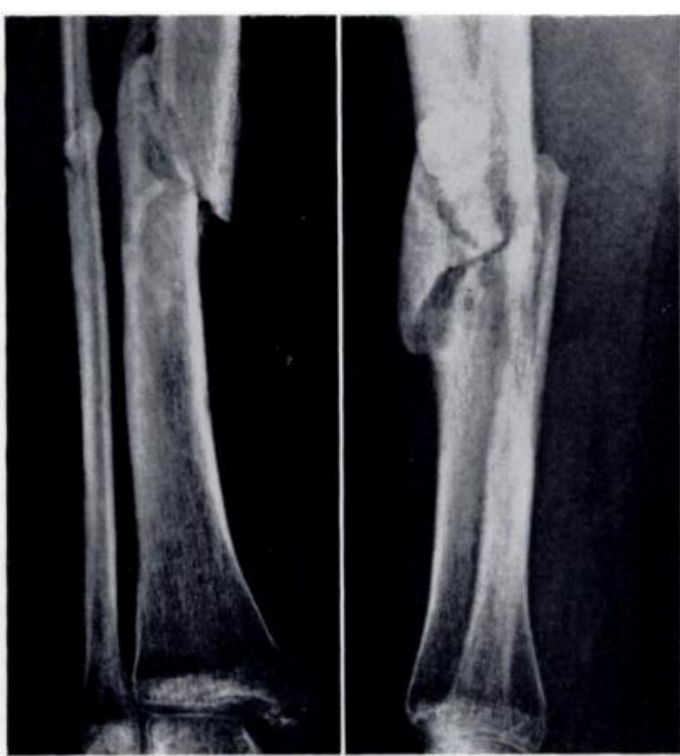

FIG. 8

Case 2. Figure 7-Radiographs of the fractured tibia and fibula. Figure 8-Radiographs 'of the fractures at fourteen weeks.

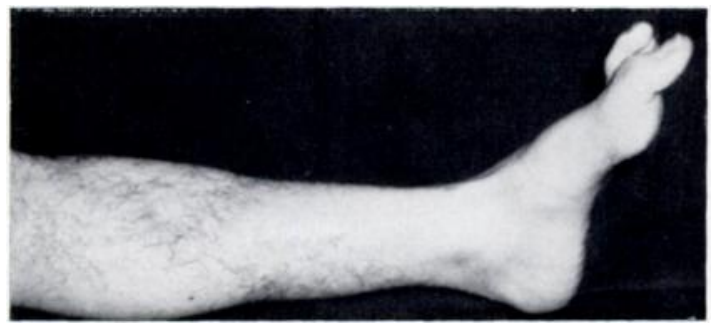

FIG. 9

Case 2-To show the fixed pes equinus and clawing of the toes.

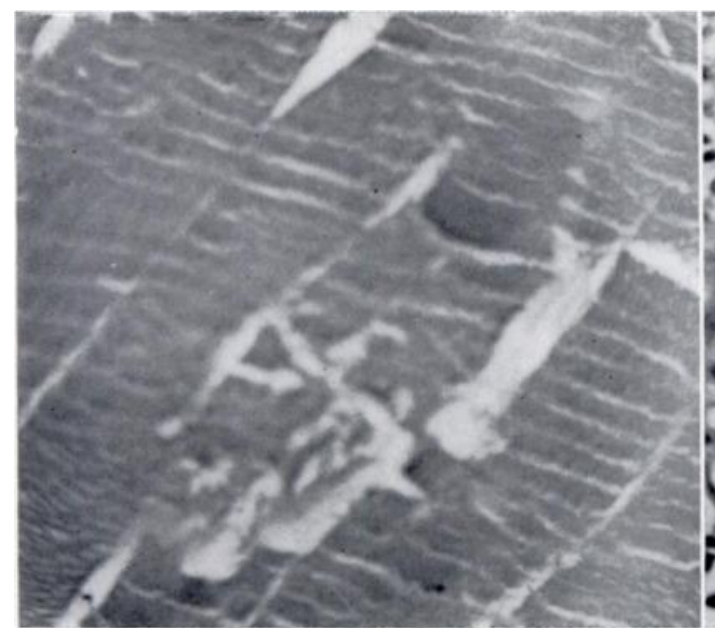

Fig. 10

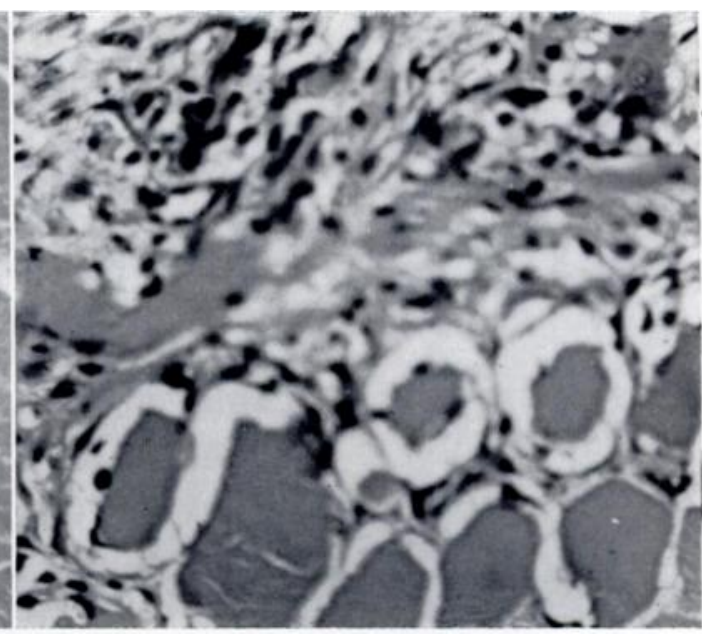

FIG. 11

Case 2. Figure 10-The histology of the necrotic muscle fibres. (Haematoxylin and eosin, $\because 192$.) Figure $11-$ The histological changes present at the junction of the fibrous capsule and necrotic muscle. (Haematoxylin and eosin, $\times 192$.)

VOL. 49 B, NO. 2, MAY 1967 
Comment-Certain features of these patients need emphasis. They were treated by well padded plasters. Pain and " burning" were not a notable feature during the first few days. The passive toe extension test was at no stage impressive, possibly because of concomitant nerve damage.

\section{REVIEW OF 100 TIBIAL FRACTURES}

These cases led us to review a series of 100 patients who had sustained tibial shaft fractures (Table I). Special attention was given to any signs of residual ischaemic change. All the patients had been treated by conservative means involving reduction, suturing of puncture wounds-in twenty-three patients-and application of padded plasters.

There were seventy-three male and twenty-seven female patients. The right leg was involved in sixty-four cases and the left in thirty-six cases. The average age was 36.5 years, and average follow-up period was forty-two months. In this group ten patients were found to have some form of ischaemic stigmata in the damaged limb (Table I). All cases with skin loss or open wounds were excluded from the series. Ninety-two patients obtained primary bony union and eight patients needed bone grafting (Table II). Of the ten patients under consideration, seven had their fractures in the mid-shaft and three at the junction of the middle and lowest thirds. Eight had closed fractures but two had puncture wounds. There were two patients with double segmental fractures (Table III).

Table IV shows the various ischaemic signs found. Eight patients had claw toes and eight had cavus deformities. Fixed equinus was present in seven; the dorsalis pedis was absent in two and the posterior tibial pulse was absent in seven patients. There were no sensory defects on the dorsal aspect of the foot, but four patients had involvement of the posterior tibial nerve. Calf wasting of more than one inch was present in nine patients.

\section{ANATOMICAL CONSIDERATIONS}

Studies by Bowden and Gutmann (1949) emphasise the anatomical factors involved in the arterial supply of the calf muscles. Great stress in the past has been placed on the fact that the upper calf muscles anteriorly are encased in a relatively unyielding fascial compartment, whereas the posterior muscles more distally are often considered free to expand unhindered (Horn 1945, Hughes 1948). A transverse section of the calf near its middle shows how close to the posterior ridge of the tibia the neurovascular bundle lies. In contrast the anterior tibial vessel at this level is distant and not so vulnerable to laceration, contusion and thrombosis. Other factors may be contributory, such as the relative metabolic demand of different muscles.

Blomfield (1945) pointed out that the gastrocnemius was supplied by a longitudinal leash of small arteries, whereas the soleus and peroneii are supplied by an anastomotic arterial chain and the long toe flexors by arterial loops. Damage to the principal artery entering the muscle is liable to give rise to fairly massive necrosis. On the other hand focal softening will occur if the intramuscular arterial tree is involved. Mozes, Ramon and Jahr (1962) rightly pointed out that the three main arteries of the calf were reciprocal in their blood supply, so that when, for instance, the peroneal artery is damaged the posterior tibial tends to take over, and vice versa. If, however, both vessels are involved massive necrosis of muscle and ischaemic changes in the main nerves are liable to develop.

\section{DISCUSSION}

In the literature the incidence of Volkmann's contracture in the lower limb following calf fractures is low. Ever since Volkmann's original communication in 1878 the lesion in the forearm has overshadowed that in the leg. Griffiths (1940) recorded that in 21,000 fractures treated at Manchester eight cases of Volkmann's ischaemia were noted, mainly in the upper 
TABLE I

Detalls of 100 Fractures of the Tibia and Fibula

\begin{tabular}{|c|c|c|}
\hline Female 27 & Right 64 & Left 36 \\
\hline Average age & . & 36.5 years \\
\hline Average follow-up & . & 42 months \\
\hline Ischaemic stigmata & . & 10 cases \\
\hline
\end{tabular}

TABLE II

TyPeS OF Fractures aNd RESULTS

\begin{tabular}{|c|c|c|c|}
\hline & & & Number \\
\hline Closed fractures & . & . & 77 \\
\hline Open fractures & . & . & 23 \\
\hline Primary union & . & . & 92 \\
\hline \multicolumn{3}{|c|}{ Secondary union after bone grafting } & 8 \\
\hline
\end{tabular}

TABLE III

Analysis of Tibial Fractures with Ischaemic Stigmata

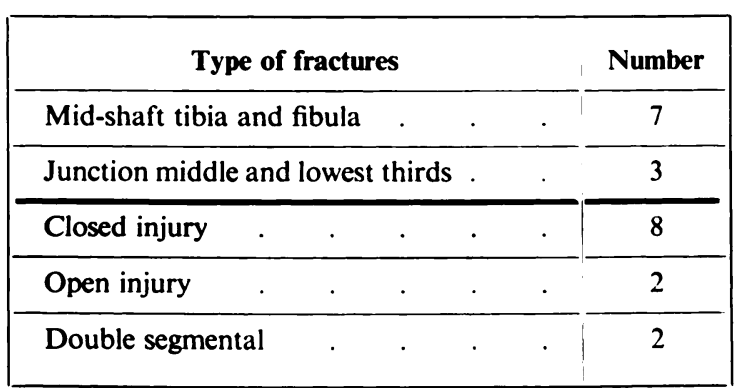

TABLE IV

Ischaemic Signs in Ten Cases

\begin{tabular}{|c|c|c|}
\hline \multicolumn{2}{|c|}{ Signs } & Number \\
\hline Claw toes & . & 8 \\
\hline Cavus foot & . & 8 \\
\hline Fixed equinus & . & 7 \\
\hline \multirow{2}{*}{ Absent pulse } & Dorsalis pedis . & 2 \\
\hline & Posterior tibial . & 7 \\
\hline \multirow{2}{*}{ Sensory defect } & Dorsal & 0 \\
\hline & Plantar . & 4 \\
\hline \multicolumn{2}{|c|}{ Calf wasting-more than one inch } & 9 \\
\hline
\end{tabular}

VOL. 49 B, NO. 2 , MAY 1967 
limb. Thomson and Mahoney (1951) emphasised the rarity of Volkmann's ischaemia in the leg. Of forty-two cases collected between 1931 and 1947 there were twenty-four which involved the upper limb and eighteen in the lower limb, of which seventeen were caused by injury to the femoral and popliteal vessels, but only one involved the tibial vessels. Horwitz (1940) collected twenty cases. Ellis (1958) in analysing disability after tibial shaft fractures showed that 6 per cent of the cases had severe ankle and foot stiffness with deformity, mainly from ischaemia. In this communication we exclude other types of vascular damage, such as the anterior tibial syndrome (Hughes 1948), femoral embolism and thrombosis, and femoral and popliteal arterial damage. We are confining our attention to injuries sustained to the vessels in the mid calf and lower calf.

Although not as disabling as in the arm, ischaemia in the calf gives rise to prolonged disability, with joint stiffness and deformity, so that every effort should be made to prevent the condition. We consider that all patients with tibial shaft fractures should be admitted to hospital in the first instance. The diagnosis of ischaemia is made by awareness of the possibility, and by carefully noting the clinical picture. The classical signs of pain, pallor, paralysis and pulselessness cannot be entirely relied upon, as shown by this study. Having made the diagnosis, simple measures such as removing external splints and warming the body generally are taken. Possibly one gentle manipulation of displaced fragments is permissible. The technique of long-term infusion treatment of the involved limb with vasodilators and low molecular weight Dextran as described recently by Marti (1963) may have a place in management of border-line cases. In general, however, if there is no improvement in the clinical picture, then the calf should be explored without delay, endeavouring the whole time to avoid further damage to the intramuscular vessels by approaching the lesion through the intermuscular planes. Extensive fasciotomy, and evacuation of haematoma may be sufficient to restore the circulation. If muscle necrosis is already present then, as suggested by Alldred (1960), the dead mass should be excised to avoid prolonged disability and late calcification. Although arterial suturing (Bonney 1963, Kirkup 1963) has been accepted practice in femoral and popliteal arterial damage, until recently repair of small diameter vessels as in the calf has not been considered technically possible. However, the recent work of Nolan and McQuillan (1965) and others has shown that this is technically possible. After operation secondary thrombosis in collateral and intramuscular vessels is diminished by giving intravenous Rheomacrodex. Hyperbaric oxygen may also be useful (Maudsley, Hopkinson and Williams 1963).

In conclusion, we would stress the importance of ischaemia as a cause of disability in tibial shaft injuries. With a view to analysing the pattern of vascular injuries in these cases we now employ routine femoral angiography during reduction of displaced tibial fractures. Seddon (1964) has said: "The threat of ischaemia in the limbs is always with us; it can be countered only by constant awareness and courageous action. I believe it will be found more commonly in the lower limb than we at present suspect." We very much agree with this view.

\section{SUMMARY}

1. The frequency of variable degrees of ischaemia of soft tissue in closed tibial and fibular shaft fractures is emphasised.

2. Two cases with ischaemia of calf musculature are described.

3. A follow-up study of 100 cases of closed tibial shaft fractures is analysed; ten patients were found to be affected.

4. The anatomical and pathological changes are discussed.

5. A plea is made for early surgical exploration in cases manifesting signs of ischaemia.

We wish to thank Mr Beverley Southern for the clinical photography, also Mrs M. Beresford and Mrs G. W. Taylor for secretarial help. 


\section{REFERENCES}

AlldRed, A. (1960): Localised Ischaemia of the Calf. Journal of Bone and Joint Surgery, 42-B, 659.

Blomfield, L. B. (1945): Intramuscular Vascular Patterns in Man. Proceedings of the Royal Society of Medicine (Section of Orthopaedics), 38, 617.

BonNey, G. (1963): Thrombosis of the Femoral Artery Complicating Fracture of the Femur. Journal of Bone and Joint Surgery, 45-B, 344.

Bowden, R. E. M., and Gutmann, E. (1949): The Fate of Voluntary Muscle after Vascular Injury in Man. Journal of Bone and Joint Surgery, 31-B, 356.

Clarke, W. E. Le Gros (1946): An Experimental Study of the Regeneration of Mammalian Striped Muscle. Journal of Anatomy, 80, 24.

EAstcort, H. H. G. (1965): The Management of Arterial Injuries. Journal of Bone and Joint Surgery, $47-B, 394$.

EluIs, H. (1958): Disabilities after Tibial Shaft Fractures. Journal of Bone and Joint Surgery, 40-B, 190.

GrIfFITHS, D. Ll. (1940): Volkmann's Ischaemic Contracture. British Journal of Surgery, 28, 239.

Horn, C. E. (1945): Acute Ischaemia of the Anterior Tibial Muscle and the Long Extensor Muscles of the Toes. Journal of Bone and Joint Surgery, 27, 615.

HorwItz, T. (1940): Ischemic Contracture of the Lower Extremity. Archives of Surgery, 41, 945.

Hughes, C. W. (1958): Arterial Repair during the Korean War. Annals of Surgery, 147, 555.

Hughes, J. R. (1948): Ischaemic Necrosis of the Anterior Tibial Muscles due to Fatigue. Journal of Bone and Joint Surgery, 30-B, 581.

KIRKUP, J. R. (1963): Major Arterial Injury Complicating Fracture of the Femoral Shaft. Journal of Bone and Joint Surgery, 45-B, 337.

MARTI, W. K. (1963): Intraarterielle Langzeitinfusionen mit Vasodilatoren und niedrigmolekularen Dextran in der Behandlung peripherer arterieller Durchblutungsstörungen. Schweizerische Medizinische Wochenschrift, 93, 1746.

Maudsley, R. H., Hopkinson, W. I., and Williams, K. G. (1963): Vascular Injury Treated with High Pressure Oxygen in a Mobile Chamber. Journal of Bone and Joint Surgery, 45-B, 346.

Mozes, M., Ramon, Y., and JAHR, J. (1962): The Anterior Tibial Syndrome. Journal of Bone and Joint Surgery, 44-A, 730.

Nicoll, E. A. (1964): Fractures of the Tibial Shaft. Journal of Bone and Joint Surgery, 46-B, 373.

Nolan, B., and MCQuillan, W. M. (1965): Acute Traumatic Limb Ischaemia. British Journal of Surgery, 52, 559.

SEdDON, Sir Herbert (1964): Volkmann's Ischaemia. British Medical Journal, i, 1587.

Thomson, S. A., and MAHONEY, L. J. (1951): Volkmann's Ischaemic Contracture and its Relationship to Fracture of the Femur. Journal of Bone and Joint Surgery, 33-B, 336.

Volkmann, R. von (1878): Handbuch der allgemeinen und speciellen Chirurgie. Band 2, Abt. 2, 846. Pitha and Billroth. Stuttgart: F. Enke.

VOL. 49 B, NO. 2, MAY 1967 